\title{
YESTERDAY-TODAY-TOMORROW: AN E-LEARNING PROGRAM ON MIGRATION
}

\author{
Bryan McCormack, YTT Association, France, Paola Perucchini, Maria Gaetana Catalano, \\ Fridanna Maricchiolo, Roma Tre University, Italy
}

\section{Background}

The present study presents an e-learning platform based on the educational programs carried out by Yesterday-Today-Tomorrow Association (YTT) and Roma Tre University. YTT is an independent Paris-based Educational \& Humanitarian Non-Profit which combines visual language with learning tools to facilitate migrants' and refugees' inclusive processes, promote human-rights, the prevention of violent extremism, freedom, diverse, multi-ethnic and multi religious societies. YTT is also aimed at positively affecting national and international migration policy-making. Since 2016, YTT has been collaborating with thousands of refugees/migrants (from more than 50 nationalities, aged from 3 to 70 years old) in over 35 camps and squats across Europe/North Africa. They receive 3 sheets of paper and coloured pens and are invited to draw 3 sketches: one of their life before: Yesterday; one of their current life: Today; and one of their life imagined in the future: Tomorrow. These drawings define the YTT visual language, a raw, emotional and explicative language that speaks logically and directly to the audience. Figure 1 shows the YTT drawings by a 9 years old Iraqi girl, living in the Miksaliste Refugee Camp (Belgrade, Serbia), who represented in her Yesterday (the first on the left) which is what she saw when on a Sunday morning, coming back from church, she found both her parents and brother killed. In the Today, she drew her hands and arms with the cuts she self-inflicts on her body. In the Tomorrow, she drew her dream to be a doctor, so that she can help others.
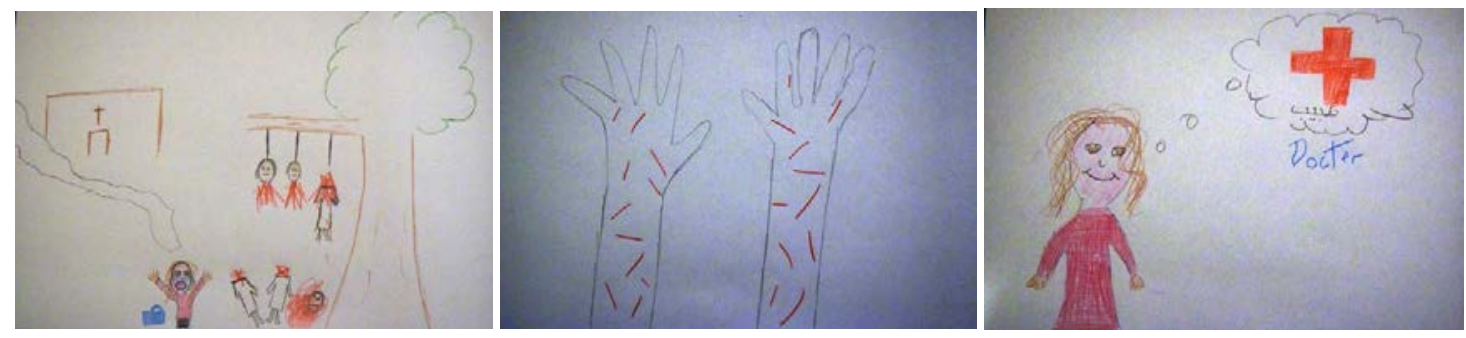

Figure 1. The Yesterday, Today, Tomorrow drawings by a 9 years old Iraqi girl currently living in Miksaliste Refugee Camp, Belgrade, Serbia.

As it is well known, through drawing, people can express clearly their thoughts and feelings independently of dialect, nationality or education (Arizpe, Colomer, \& Martínez-Roldán, 2014). Thus, migrants can leave their own trace, creating their own contemporary culture and voice, whereas simultaneously losing all traceability of their inherited culture. 
All of these drawings, along with some basic information (age, gender, nationality and current location, etc.) have been collected, filed, scanned and now makeup a digital database of thousands of voices, which is constantly updated with new drawings.

Each drawing has been also analysed and coded, considering different elements regarding the author of the drawing, the content, and the graphical features. With respect to the author, gender, age, nationality, camp (name/city/nation) are analysed. With respect to the content, we code the presence of elements representing human figures, emotions, war, blood, boat, tears, family, school, constructions, barbed-wire fences, animals, vegetables, sky elements, writing, flags, symbols, etc. For the graphic features, tools (pen or pencil) and colours, specifying the precise colour present, are considered. This YTT electronic visual catalogue of drawings allows selecting specific drawings for specific educational programs.

\section{The YTT educational program}

The educational program has the aim to stimulate awareness of the living conditions of migrants and refugees, promote deconstruction of prejudice and reduction of discrimination practices, raising awareness among students to fundamental human rights and cultural differences.

Since the early years of life, children show social discrimination and preference for persons and toys similar to their own ethnic (Kinzler et al., 2007; Kelly et al., 2007), which are influenced by adult and peer socialization processes (Aboud \& Doyle, 1996). School results to be of optimal context to contrast the development of ethnic prejudice (Hello et al., 2004; Baron, 2015; Bigler \& Liben, 2006). The intergroup contact theory by Allport (1954) has been demonstrated to be effective in the reduction of prejudice; and more specifically, educational strategies that promote real or imaginary contact results are successful (Batson et al, 2002; Birtel \& Crisp, 2012). Thus, we created an educational program for pupils in schools using the YTT visual language to produce an imaginary contact with a migrant/refugee of the same age.

The educational program was carried out with around $2005^{\text {th }}$-grade children from five primary schools in Rome. It used student-centred strategies, which activate empathy and perspective taking, creating a contrasting effect between their own experiences and migrants'/refugees' experiences. The goal of these activities was to stimulate a deep emotional understanding of the migration experience.

The fundamental part of the program concerns activities in which children were asked to draw their YTT drawings, i.e. their past, present and future; then, to draw an imaginary migrant age-mate's YTT drawings; and finally, to look, describe and reflect on migrant children's YTT drawings (see Figure 2).

Pupils and teachers involved in the program showed great appreciation and interest, and schools' principals have asked to include other classes and continue next year. During the lessons, children expressed emotional engagement, non-verbally and verbally, and 
understood the migrants' condition. They seem also to change their attitudes towards migrants; as a child told, at the end of the program,

"Now, when I go into a cafe and I see a refugee in front of it, I ask my father to buy an extra croissant and I give it to him" (Marco, 10y).

To verify the effects of the educational program on pupils' prejudice, a pilot study was conducted. Participants were 99 children (a subgroup of the pupils involved in the program) distributed in experimental $(n=56)$ and control $(n=43)$ groups. Explicit and implicit prejudice were evaluated with standardized tests (Pirchio et al., 2018). Preliminary results show a statistically tendency to reduction in implicit prejudice in the experimental group $(\mathrm{t}(38)=1.73, \mathrm{p}=.09)$ but not in the control group, and a reduction of explicit prejudice for both groups (experimental group $\mathrm{t}(43)=2.45, \mathrm{p}=.019$ and control group $\mathrm{t}(16)=3.27$; $\mathrm{p}=.005)$.
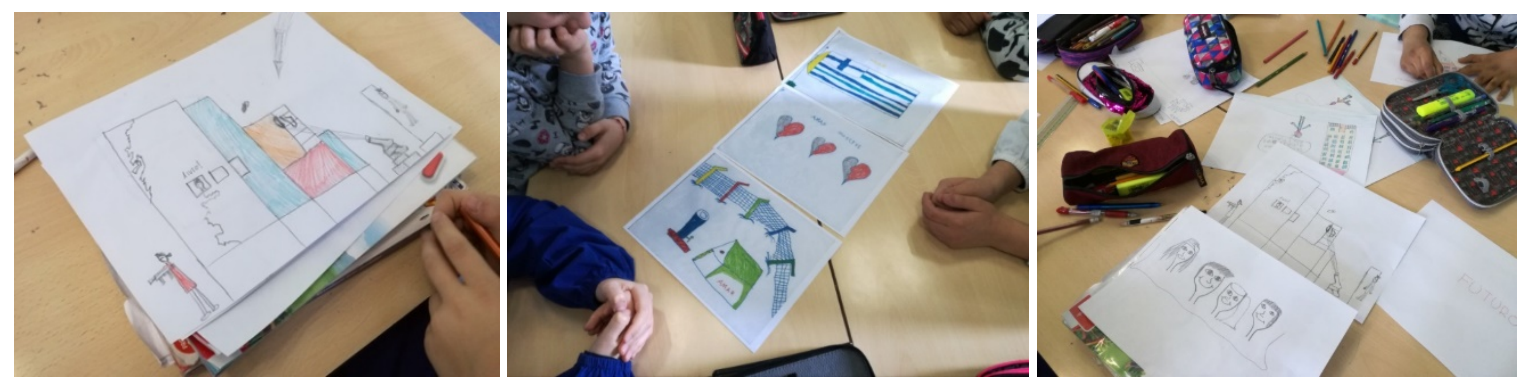

Figure 2. Pupils during the drawing activities

\section{"Exploring the world around us": YTT e-learning Italian version}

Based on the research experience described, the e-learning program was created to provide a tool and a guide for teachers to utilize the YTT educational program presented above. A learning platform is implemented which contains a teacher tool-kit, a YTT drawing database and other materials such as suggested activities, information, additional tools that could be combined with the drawings in the educational activities.

Currently, two programs are available: a two hours lesson and a five lessons program. For both versions, the e-learning program defines learning objectives, activities and strategies to realize them. The tool-kit is organized in an easy format so that teachers can download, print and use it to help realize the lessons. The YTT drawing visual database, organized as a catalogue, allows teachers to choose the refugees' drawings more suitable for their educational, social, cultural, ethnic context.

\section{Future directions}

The aim is to use the YTT e-learning platform at a global level to contribute to the refugee/migrant crisis. To reach that aim, the "Exploring the world around us" - Italian platform will be adapted for different strategic or at-risk regions, such as, Bosnia \& Herzegovina, Turkey, Morocco, Lebanon and Bangladesh, countries where the YTT Association has established contacts with local authorities, universities and NGO's. 
Moreover, the program will be addressed to three different topics: "Global Warming", "Women's Rights" and "Children's Rights". For each of them, specific drawings will be selected. The program on "Global Warming" will include drawings coming from climate migrants and in the same way, the programs "Women's Rights" and "Children's Rights" will adopt drawings realized respectively by female and children refugees/migrants. The reasons for having multiple programs are numerous, i.e. proposing different approaches to the refugee/migrant crisis; addressing such vital issues as Global Warming/Women's/Children's Rights from a completely unique and powerful angle; giving more options to teachers/schools/authorities in certain regions and countries where for different political and/or ideological reasons it can be complicated and/or dangerous to address directly headon the refugee/migrant issue

\section{References}

Aboud, F. E., \& Doyle, A. (1996). Does talk of race foster prejudice or tolerance in children? Canadian Journal of Behavioral Science, 28, 161-170.

Allport, G. W. (1954). The nature of prejudice. New York, NY: Addison-Wesley.

Arizpe, E., Colomer, T., \& Martínez-Roldán, C. (2014). Visual journeys through wordless narratives: An international inquiry with immigrant children and the arrival. A\&C Black.

Baron, A. S. (2015). Constraints on the development of implicit intergroup attitudes. Child Development Perspective, 9, 50-54.

Batson, C. D., Chang, J., Orr, R., \& Rowland, J. (2002). Empathy, Attitudes, and Action: Can Feeling for a Member of a Stigmatized Group Motivate One to Help the Group? Personality and Social Psychology Bulletin, 28(12), 1656-1666.

Bigler, R. S., \& Liben, L. S. (2007). Developmental intergroup theory: Explaining and reducing children's social stereotypes and prejudice. Current Direction in Psychological Science, 16(3), 162-166.

Birtel, M. D., \& Crisp, R. J. (2012). “Treating” prejudice: An exposure-therapy approach to reducing negative reactions toward stigmatized groups. Psychological Science, 23, 13791386.

Hello, E., Scheepers, P., Vermulst, A., \& Gerris, J. R. M. (2004). Association between educational attainment and ethnic distance in young adults: socialization by schools or parents? Acta Sociological, 47, 253-275.

Kelly, D. J., Liu, S., Ge, L., Quinn, P. C., Slater, A. M., Lee, K., et al. (2007). Cross-race preferences for same-race faces extend beyond the African versus Caucasian contrast in 3month-old infants. Infancy, 11, 87-95.

Kinzler, K. D., Dupoux, E., \& Spelke, E. S. (2007). The native language of social cognition. Proceeding of The National Academy of Sciences, U.S.A. 104, 12577-12580. 
Yesterday-Today-Tomorrow: An e-Learning Program on Migration

Bryan McCormack et al.

Pirchio S., Passiatore Y., Panno A., Maricchiolo F., \& Carrus G. (2018). A Chip Off the Old

Block: Parents' Subtle Ethnic Prejudice Predicts Children's Implicit Prejudice. Frontiers of Psychology, 9, 110. 